\title{
The Evolution of Viral Marketing to Improve Business Communication
}

\author{
Giuseppe Granata ${ }^{1} \&$ Giancarlo Scozzese ${ }^{2}$ \\ ${ }^{1}$ Departement of Economics and Law, University of Cassino and Southern Lazio, Cassino, Italy \\ ${ }^{2}$ Department of Human and Social Sciences, University for Foreigners, Perugia, Italy \\ Correspondence: Giuseppe Granata, Department of Economics and Law, University of Cassino and Southern \\ Lazio, Cassino (FR), Italy. \\ To conform to the Italian regulations on academic publishing, even though the article is the joint work of all the \\ authors we attribute the contribution of each author as follows: Giuseppe Granata, sections: $1-2$ and 3; \\ Giancarlo Scozzese, sections: 4 - 5 and 6.
}

Received: November 15, 2018

Accepted: November 26, 2018 Online Published: November 29, 2018

doi:10.5539/ibr.v11n12p105

URL: https://doi.org/10.5539/ibr.v11n12p105

\begin{abstract}
To win the consumers attention, more prone to advertisement, it is essential that companies interact with them. Equally important for the effectiveness of an advertising campaign is the ability to involve, amaze and entertain users in such a way as to encourage them to talk about a brand or product, spontaneously triggering a viral word of mouth. To achieve this, companies use different communication tools, especially web communication and digital marketing.

Companies can choose to approach to these new phenomena, read them, understand them, interpret them, research and identify new advantages and opportunities; then start a process of change aimed at adapting the organization to a model that is able to fully exploit these phenomena. Or they could choose to ignore them, distance them, close their eyes, pretend they do not exist, convince themselves that they are only transitory phenomena of a technological nature and lacking relevance for the business.

The goal of the work is to verify how the viral marketing instrument can help improve and strengthen business communication. In fact, by now, there are many companies that have decided to support and, in some cases, replace traditional communication with online communication.
\end{abstract}

Keywords: digital marketing, online communication, word of mouth, viral marketing

\section{Introduction}

One of the main objectives pursued by viral marketing is the search for a viral idea. Godin (2000) talks about idea virus in this regard: "an ideavirus is a fascinating idea that spreads through a part of the population, changing and influencing whoever you meet". Viral marketing therefore plans to "include" an ideavirus in the sales objective and implements strategies to facilitate propagation. It would perhaps be simplistic to think of viral marketing as a "technique aimed at encouraging word of mouth" (Rubino, 2009).

Specifically, it refers to "a type of non-conventional marketing that exploits the communication skills of a few stakeholders to transmit the message to an exponential number of end users. It is an evolution of word of mouth, but it is distinguished for the fact that it is on a voluntary intention from the campaign promoters' part. The principle of viral marketing is based on the originality of an idea: something that, due to its nature or its content, is able to expand very quickly in a given population » (Venturi \& Covino, 2009)

In merit of its origins, the word viral marketing was created for the first time by Steve Jurvetson and Tim Draper, to explain the incredible success experienced by Hotmail in 1997. It was July 4, 1996 when Hotmail founders Jack Smith and Sabeer Bhatia launched the first successful viral marketing action, including the following message at the end of each message sent from a hotmail.com mailbox: "PS. Get your free e-mail account at http://www.hotmail.com.".

To enter the message, immediately understood, was the same company providing the service; to give the advice, however, was the sender of the e-mail. The result? After 18 months Hotmail reached 8.7 million users. This 
shows how the web can allow a rapid and widespread dissemination of any content between users of the network, in full analogy with the spread of epidemics caused by viruses.

The use of digital means allows in fact to increase the classic word of mouth to excess. However, online media are not the only ones that can be used to trigger an epidemic: nothing prevents the viral marketing from exploiting off-line tools. A famous example is offered by the company Volkswagen that in June 2009 has created an advertising campaign called "The fun theory" with the objective, not immediately visible, to associate the brand with the value of environmental responsibility, to attract the attention of the recipient on the new ecological cars.

One of the campaigns launched (named "floor stairs"), which took place in Odenplan, Stockholm, has provided for the application of panels on the stairs at the exit/entrance of the undergrounds, visually transforming them into a piano keyboard to be played while walking it. So, to show that to change for the better people's behaviour the easiest way to follow is to make things fun, it has been chosen to analyse the attitudes held by passers-by in such context: normally the majority of the people use the escalators for comfort. It turned out that $66 \%$ more people (compared to the normal average) chose to have fun playing the stairs.

This off-line campaign was then broadcasted online, where the video was viewed about a million times in October 2009. Another campaign that really conquered everyone was certainly the one carried out by Algida, the leading brand in the sector in Italy and in Europe, which celebrated its 70th anniversary and, to best honour the traditional line of products that made the history of the company, has focused its communication campaign on "The classics of all time", that is, it concentrated on those ice-cream present in the market practically always and intended to attract future generations, namely the Liuk, the Cremino, the Crispy and the Fior di Fragola.

In fact, during the communication campaign for summer 2016 the Algida classics come to life, catalysing the attention of passers-by in a truly original way: the four "colds" protagonists, in fact, resuming some dialogues that bring to mind films, songs and funny daily skits, able to snatch anyone's smile.

\section{The Evolution of Viral Marketing.}

Regardless of the support used, however, what counts in a viral marketing strategy is the initial impulse. One of the most recent evolutions of viral marketing is the birth of the influencers, that is, people who are more experienced than others to spread the message. Identifying and courting the influencers is therefore one of the key factors for achieving success (Rubino, 2009).

It should be pointed out, however, that when the spread occurs on the net, the term word of mouse is used (because the spread is done by a mouse click and not by word of mouth) and comes to life when a consumer gives information to another consumer. Each person has his own social network, made up of relatives, friends, and colleagues.

On the Internet this social network is greatly expanded thanks to social networks. In fact, new consumers are no longer happy to find the technical characteristics of the product or the advertising messages of companies on the net, but seek advice on purchases and before buying they are informed on the web, read reviews and comments, listen to the experiences of purchases from other consumers, ask for advice from experienced and reliable users.

The Word of mouth marketing is born on the assumption that people love to talk about products, services, relationships (not only verbally but also on blogs on the web, forums, social network, ...) and consists in trying to give people a way to talk about products or services of their own company and make it a point in trying to make these conversations start easily. The word of mouth marketing therefore consists in trying to encourage and gain positive recommendations from the people themselves (Granata, 2016).

Another evolution in viral marketing is given by the mode of diffusion of the message and the speaker subject. Thus we can identify 2 main categories:

- frictionless

- active viral marketing.

In the frictionless viral marketing, the information about a particular service / product is unconsciously spread by the user, as happened with Hotmail in the example already mentioned.

Characteristic of the active viral marketing instead is the active role of the divulger. In fact, the user has control over the viral message and is a pro-active transmitter.

In the coming in of the active viral marketing category, moreover, there are more cases, distinguishable in relation to the degree of involvement and the motivations that push the transmitter to become an influencer: 
Social viral marketing: occurs when the user is pushed to the viral for reasons of social recognition, understood as belonging to a restricted and privileged circle of users. This is not an example of the viral marketing strategy realized at the time by Gmail: the e-mail box could be activated only upon invitation by a person who has already used it;

Viral marketing in strict sense: manifests itself when the user benefits from the highest number of members or from the major activations promoted by himself. This is the case of instant messaging systems.

Incited viral marketing: it is found when the user is encouraged to disclose the message from economic and non-economic advantages. Viral games and advergames fall into this category. (Pastore \& Veernuccio 2008).

\section{Objectives and Strategies}

It is important that people talk about it: this is precisely the goal and the active principal of viral marketing. The basic idea is to induce people with a message or product that is so irresistible as to spread like a social epidemic. It is the path that a virus normally takes, emanating from one infected person to another, being transmitted freely in the air (Calicchio, 2006). Thus, in a metaphorical sense, as the viruses spread in the air, even the messages require a valid support to reach the greatest number of people in the shortest possible time.

There are many alternatives to this effect: for the launch of a viral marketing campaign, many tools can be adopted, such as traditionally the e-mails, banners, links, or off-line, free samples. However, the multiplication of viral initiatives based on these channels has generated over time an addiction, which has led to a loss of their effectiveness. For this reason, we aim to use new communication systems, more technological and able to arouse greater interest than other forms of simple propagation.

Therefore, it deals with newsgroups, forums, community but also viral videos, advergames, virtual sending (virtual postcards, screensavers or ringtones), recommendation systems. In Wilson, (2000) an e-commerce consultant, developed 6 principles that need to possess a viral marketing strategy to work.

Table 1. Viral Marketing Principals by Wilson 2000

1. Offer free products or services.

2. Be easy to share.

3. Use existing communication systems.

4. Take advantage of motivations and common behaviour.

5. It must be easily scalable.

6. Take advantage of the resources of others.

Source: Wilson R.F. (2000)

1. Free products or services.

Giving away valuable products or services is the key element of most viral marketing plans. "Free" attracts attention and this, once captured, can easily move to other products or services that we offer for a fee. An example is WhatsApp, a smartphone messaging app that allows you to exchange messages and audio files, videos or images with own contacts without having to pay for SMS. The app provides a trial period of one year as from installation: thereafter there is an annual fee of 89 cents. The i-Phone users on the other hand do not pay for an agreement established with Apple.

\section{Be easily shared.}

Viruses spread when they can be easily transmitted. From the marketing point of view, the message, in order to be easily transmissible and without distortions, must be as simplified as possible. Precisely for this reason, the media that have to transmit the message must be easy to share. And that's why viral marketing works on the network because communication is simple, instant, quick and inexpensive.

\section{Use existing communication systems.}

The majority of people live on sociality. Each individual makes part of a small network (restricted network) consisting of 8 to 12 people between relatives, friends and groups. But it is also true that there is also another type of extended network made up of hundreds, if not thousands of contacts. This extended network of contacts depends mostly on the role that the individual repeats in society.

4. Take advantage of common tensions and behaviour.

Ingenious Viral Marketing plans take advantage of common emotional tensions. Desire is what drives people. The desire to communicate something has produced millions of websites and billions of e-mails and conversations. By identifying an emotional tension, an uncovered nerve that triggers common behaviours, a winning strategy is built. These are the emotions that drive people. 


\section{It must be easily scalable.}

To propagate as a disease, the object of viral marketing must be shared easily both by technologically advanced ones and by those who are not yet familiar with the technology. If the virus kills the host before it has transmitted it, the pandemic does not occur. In this sense it must be scalable.

6. Take advantage of the resources of others.

The most creative strategies, to facilitate their propagation, exploit the resources of the people with whom the message comes into contact.

\section{The Video and the Mobile: Sharing of Influencers}

Today's context is extremely competitive, populated by a multitude of actors who together communicate massively and insistently, but without creating more often a link with the consumer, passive and distracted is limited to observe, without being able to seal an engagement lasting over time. All forms of communication end up short-lived if not supported by a strong and direct mantra, which captures the attention of consumers and enlivens up their imagination, involving them emphatically. But some form of dialogue with the consumer seems to be lucky, if we consider the advertising developed through video, published mostly on social networks, but in general on the various websites and online platforms.

Since the duration tends to be greater than the 30 " spots broadcast on TV, they enjoy greater attention from the consumer than other forms of advertising, only if they possess two basic requirements: an interesting first frame that intrigues the audience, which pushes the audience to press "play" and at the same time an intense narration, which makes the audience an accomplice of the story that is being told.

Viral marketing video is a free form of advertising that is achieved by using video sharing portals, for example, video sharing websites. This strategy has experienced exponential growth, and today offers significant opportunities to reach a broad audience (Iavazzo, 2009).

It is fundamental to understand who we have in front of us, to create the content to convey through a proper language, to "engage" and persuade the public in a relevant way. There are some recurring elements that should be taken into account in the creation of a video, such as the choice of the title that should not be taken for granted and above all must not disregard users' expectations. The choice of thumbnail, or the preview image in the video, is usually a frame taken from the video itself but lately YouTube has allowed us to choose another image to describe the video. The sharing by influencers, who will share the video with their own network, reaching an increasing number of users.

The content has its great importance, videos with children, dogs and cats are practically a guarantee of success, as they arouse emotion, fun, create empathy by emotion. Keeping in mind the timing, hardly a video of one or more hours will become viral. The shorter it is; the more users will be willing to "invest" their time in watching the video. There are many platforms that allow you to publish movies, but if we want our video to become viral, even the platform is important. The best is definitely YouTube, which has over a billion users, almost a third of all users on the Internet, generating billions of views. The number of hours that people spend watching videos, also known as watching time, on YouTube increases by $60 \%$ annually, the fastest growth recorded in 2 years. Born in February 2005, it has expanded the promotional force of viral videos. In fact, it is right around this channel that many videos rotate to show how it is possible to do marketing and advertising in a striking way. Moreover, even on a global level, YouTube is at the top ranking amongst the most consulted sites, even settling in second place.

The strength of YouTube lies in its flexibility and easy to use: without registering you can have access to millions of videos of all kinds, those mostly watched end up on the front page. This is precisely the goal of a visibility strategy conducted on YouTube: make sure you end up on the most viewed video page of the day.

An interesting aspect in this regard, concerns videos generated directly by users (user generated content): these often receive a greater success than those created by the agencies. This trend, which at first did not affect the sphere of marketing and the interest of brands, still linked to a traditional advertising production, has spread a new custom: that of fake video. In fact, to try to break down the typical aversion of users towards traditional advertising, advertising agencies are increasingly projected to the achievements of fake videos, namely apparent amateur.

In this way the user's defences are less restrictive, passing the advertising message more easily. Numerous examples of success, not only referring to user generated content videos, are collected within the YouTube Advertisers channel, launched by the same team of YouTube in collaboration with the Art Directors Club Global. 
The site is entirely dedicated to the collection of successful case histories related to the use of YouTube as a marketing tool, showing that an excellent way to make a video or any other digital content popular is to capture the attention of the user completely, with a really contagious idea. Everything that entertains in a simple and immediate way on YouTube works. Short videos work, able to create a trend, a fashion, a way of being.

The growing popularity of smartphones and broadband in Italy, pushes many companies to communicate with their consumers via mobile devices. This market is certainly a valid field for proposing innovative marketing strategies. In fact, mobile devices (PDAs, smartphones, tablets, etc.) present some interesting features:

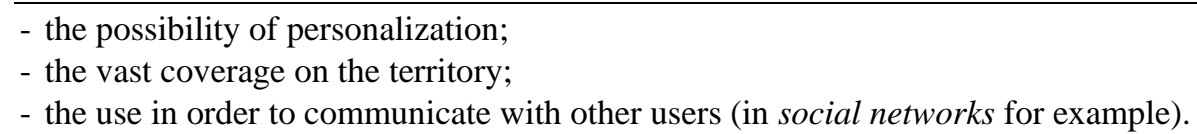

The share of mobile marketing has now exceeded $20 \%$ of online advertising, but about $80 \%$ is in the hands of the big players of the web (above all Facebook and Google). A market that is dragged by social networks that collect almost $60 \%$ of advertising revenue thanks to the ads displayed on smartphones, from the most relevant video and rich formats. We are an increasingly connected people, Audi web confirms that around 1 Italian in 2 is connected to the Internet. In 2015 on average we find online 29 million users in the month and about 22 on the average day, in fact you check your mobile phone 150 times a day.

On the basis of socio-demographic data, it still confirms a significant diffusion of the daily use of the network by the younger segments of the population. In fact, the daily use of the Internet is widespread mainly among 18-24 year olds $(67 \%, 2.8$ million users) and 25-34 year olds (66\%, 4.6 million), among the most active even in fruition of mobile internet.

On the one hand, therefore, the demand grows, on the other the supply is structured. According to a study, in $2016,50 \%$ of companies declared that they do digital marketing, but do not have a precise strategy, while $16 \%$ consider mobile marketing as a separate activity compared to other marketing strategies. The objectives generally pursued by a mobile marketing campaign can be regarded:

- increase of brand awareness

- database generation of opt-in client profiles (volunteers)

- increase in customer loyalty.

- increase in sales (Rubino, 2009).

However, there are many innovations in this regard: recently, many applications have been designed to be downloaded directly to mobile devices. These are service applications or games and fun applications. Other tools that can be used are micro-browsing sites or sites designed for mobile phones, or even QR Codes and Data Matrix (Semacode), consisting of two-dimensional barcodes readable by mobile phone.

A QR code could improve, for example, the customer's shopping experience by providing information on the products he intends to purchase and also, based on past customer purchases and previous browsing activities, suggestions about menus, diets or combinations of food, clothes, etc. and could also allow the sharing of information and suggestions with other customers, friends or enthusiasts. (Mobile Marketing Observatory \& Service, 2007).

At the same time, some companies are experimenting with the downloading of advertising games as an advertising mechanism with two types of delivery models:

- advertising games, or games, developed with different types of languages (Java, ActionScript etc.), which contain the concept or elements of the brand identity or of the communication campaign in progress;

- ad-funded games, or those games in which advertisements are inserted during the upload phase.

The feature that unites the two types and the possibility of being used for free (except for the payment of the possible data traffic). The objectives pursued by the companies through the two tools are different: the advertising games stimulates the user to become more familiar with the brand and to interact with the company, for a longer period, having fun; through the ad-funded game, a pure advertising campaign is carried out (Osservatorio Mobile Marketing \& Service, 2007). In short, the mobile allows the person to reach people the moment they are making a purchase or are experiencing a particular experience.

The seasonal plan on the mobile should include not only promotional activities but also aimed at engagement: Starbucks for example has created a calendar of initiatives for customers who use their app that includes both weekly offers, and the opportunity to taste the specialty of the period, whether or not to receive thematic 
greetings. Compared to traditional media, mobile makes it possible to reach consumers at any time, given that every person keeps their smartphone (and on the lookout) constantly at hand, and in many ways: messages and push notifications are immediate means of contact, that easily attract the user's attention, it is estimated that $99 \%$ of the messages are open within 90 seconds of receiving them.

From the mobile, more and more people access directly to the app, without going through the browser. In 2017, 279.628 billion app were downloaded worldwide and it is estimated that in 2018 it will be 324.801 billion. Having a site optimized for each device is a fundamental point in the mobile marketing strategy. $47 \%$ of people expect a site to load on their smartphone within 2 seconds and $40 \%$ tend to abandon it within 3 seconds if it does not load correctly, also Google has started to penalize in the ranking of results sites that are not mobile friendly (in searches made on the smartphone engine).

\section{Discussion.}

«Some of the most effective and powerful messages that can affect a company and its products come from outside the organization and are beyond the control of marketing managers» (Lovelock \& Wirtz, 2007, page 216). These messages, transmitted from one individual to another in an informal way, are an excellent tool for indirect communication, and perhaps the most powerful of all. Making sure that a positive word of mouth is triggered is the ultimate goal of every organization. It is well known, in fact, that customers' recommendations to consumers represent the best type of promotion for a good, a service, and a company as a whole.

Typically, the word of mouth can be defined as spontaneous communication from person to person, between a communicator and a recipient. It "acts as an" amplifier "of experiences made by individual consumers, who are transferred to other subjects. Through word of mouth, positive experiences are transferred, to make others participate, or negative experiences to "take revenge" for the disservices suffered or the poor quality of the service received by the company or organization, or to "protect" other potential buyers "(Mauri, 2002, p.5). It is therefore important, given the implications that may derive from it, to ensure that customers are satisfied overall.

However, this is not the crux of the matter. What we want to clarify in such context is because the word of mouth, one of the oldest forms of communication in existence, still arouses such great interest today. This practice has always existed, and is universally recognized as the oldest and most natural form of marketing communication (Mauri, 2002); only recently, however, this has been realized on account of the loss of effectiveness on advertising and traditional marketing, communication mechanisms based on word of mouth could be a valid solution, given their high credibility.

In fact, coming from completely disinterested sources (such as friends, acquaintances, family members, neighbours, etc.), advice and recommendations are more credible than any other form of paid communication, including advertising (Blythe, 2006). These characteristics make the word of mouth one of the strongest forms of communication, but at the same time more fearful because it can trigger off regardless of the company's will, and difficult to manage (Granata \& Scozzese, 2017).

These considerations, together with the recent changes that have led to greater consumer power over companies and the development of new communication technologies, have led to focus once again on this phenomenon, now amplified more than ever. The advent of the Internet has in fact increased the possibilities, available to consumers, to gather impartial information on products from other consumers and provide, in turn, to release others, thus engaging in actions of electronic word of mouth (e-word of mouth or word of mouse). It, together with the practice of viral marketing, is outlined as a new form of non-conventional marketing able to spread a brand message and to conquer and infect contemporary consumers.

To achieve the desired effects, whether the spread takes place on the Internet or outside, viral marketing investments should focus on engaging an initial group of users capable of performing the function of an ideavirus connector. These are the so-called opinion leaders that means people endowed with such a charisma that they are able to influence the behaviour and ideas of a large number of individuals (Pastore \&Vernuccio, 2008). The mechanism of influence is based on the fact that opinion leaders are people much more permeable to information than others, participate intensely in the life of their community, and are endowed with strong charisma and credibility, strongly inclined to novelty, extremely curious and with a high level of confidence in the digital network. For the purposes of dissemination, however, a propensity for the influence of the exchange of information is not sufficient.

It is certainly necessary to motivate the individual to propagate the ideavirus: an advantage, in economic terms, in terms of social recognition or sharing of the opinion leader's experience. Just enough to distinguish influencers rewarded by those by vocation. In addition to creating an innovative idea, it is therefore important to identify the 
right individuals to start influencing. Gladwell, (2001) argues in this regard that, for an effective viral marketing action, the determining factors, as well as the speakers, such as the subjects capable of spreading the message influencing the recipients, are:

- viscosity or stickiness, meaning the creation of a sticky (viscous) message, able to remain in the receiver's memory;

- a network, meaning an environment in which the message can be spread in a simple and effective way.

At a later stage, according to the author, just as happens in epidemics, the idea would explode, to the point of infecting huge masses of individuals. This reaction, this sudden change, would occur once the tipping point is reached, the critical point able to trigger gigantic chain reactions. Malcom Gladwell, analyses in detail the process of dissemination of these ideas in a population.

The thought of Seth Godin, an American essayist considered the preceptor of marketing, is interesting in this regard. In his book "Purple cow" and in his other works, he takes up and reworks the idea of Geff Moore, in describing the way in which ideas are propagated within a population.

According to the author, the spread would take place exponentially, thus affecting an ever-increasing number of consumers, to reach them all. The phenomenon can be expressed graphically by a bell-shaped curve whose initial feature is constituted by the innovators and early adapters, the central one by the majority and the final one by the latecomers. The horizontal axis represents the different groups that the idea meets over time, while the vertical axis represents the number of people present in each group.

The author then argues that in spreading, a new idea would follow the trend proposed by the graph: first would affect the innovators, for them to own the novelty is a pleasure, an almost irresistible drive, then the early adapters, do not buy something new only because it's new: but they want to be updated, fashionable. As soon as the new product begins to spread, they feel authorized to buy it and in successive stages, the majority the one early, the other late. The majority is so comfortable with the products and services it uses; that does not want to change.

Finally, the latecomers or people for whom novelty is a nuisance, a danger, is to be avoided as long as possible and therefore the last to buy one. Thus, in viral marketing, what counts is the ability of the initial target (the innovators) to influence certain groups of consumers, unlike what happens with traditional methods, where it is necessary immediately, to reach the majority of spectators. This consents to reduce time and money to inform the rest of the public. Target selection is of fundamental importance in any viral marketing strategy; it is therefore essential to turn to a group of individuals who are able to influence, with a moderate expense, the purchasing behaviour of other consumers.

\section{Conclusion.}

Companies can choose to approach these new phenomena, read them, understand them, interpret them, research and identify new advantages and opportunities and then start a process of change aimed at adapting the organization to a model that is able to fully exploit these phenomena. Or they could choose to ignore them, distance themselves, close their eyes, pretend they do not exist, convince themselves that they are only transitory phenomena of a technological nature and lacking relevance for the business.

Regardless of the choices of the individual companies, these phenomena will continue their development, users and consumers will have an increasingly central and decisive role for the company's businesses, they can contribute to the launch or downfall of an organization and its products, at least in terms of image and communication. It is therefore up to companies to choose whether to change or stay, whether to grow or grow old, but aware that the numbers of this great opportunity are surprising and growing and that in 2017 Internet users worldwide exceeded 3.5 billion.

Marketing must be understood not as something aimed at selling exclusively, but aimed at the exchange. The ability to communicate and transfer value is fundamental and here social media can play an essential role, both in managing the relationship between companies, cultural organizations and the user/customer of the proposed offer, and in soliciting the desired response from the public/objective, that is the target in consideration.

Social media marketing represents an operational application of relationship marketing, as it aims to build an effective network where mutual profit relations are established, aimed at satisfying the parties, using the tools offered by the social networks.

A well-defined digital strategy ensures that the website, social media and other tools available to the organization, such as for example blogs, are integrated in synergy and their management is consistent with the mission and vision 
of the company. Online communication must always be coordinated with the offline component and must be part of a dynamic organizational system, structured in concrete and measurable objectives; this requires the involvement of all the staff of the organization, who must share the objectives, ideas and work activities with the public.

\section{References}

Blythe J. (2006). Essentials of marketing, Pearson education limited; ed. italiana: Cerdola E. (a cura di), Fondamenti di marketing, Pearson Education Italia, Milano.

Calicchio, S. (2006). Trasmetti il Virus, Lulu.com

Gladwell, M. (2001). The Tipping Point: How Little Things Can Make a Big Difference, Little Brown \& Company, New York.

Godin, S. (2000). Unleashing the ideavirus, Do You Zoom, New York.

Granata, G. (2016). Business Communication 2.0, Aracne editor, Roma.

Granata, G., \& Scozzeze G. (2017). The Influence of Virtual Communities in Marketing Decision in International Business Research, Vol. 10 n$^{\circ}$ 12, ISSN 1913-9004, doi:10.5539/ibrv10n12p191.

Iavazzo, V. (2009). I segreti del video marketing. Strategie e tecniche segrete per guadagnare e fare pubblicità con i portali di condivisione video, Bruno editore, Roma.

Lovelock, C., \& Wirtz, J. (2007). Services marketing: people, technology, strategy, Pearson education.

Mauri, A. G. (2002). The quality of firm's output as factual communication: The role of word-of- mouth Sinergie, 59.

Pastore, A., \& Vernuccio, M. (2008). Impres e comunicazione. Principi e strument per il management, Apogeo Editore, Milano.

Rubino, G. (2009). Mobile viral marketing. Come usare il marketing virale nella comunicazione mobile, eboogle

Venturi, A., \& Covino, G. (2009). Web marketing per le PMI. Guida alle nuove opportunità di business e di comunicazione, Editrice UNI Service.

Wilson, R. F. (2000). The Six Simple Principles of Viral Marketing, Web Marketing.

\section{Copyrights}

Copyright for this article is retained by the author(s), with first publication rights granted to the journal.

This is an open-access article distributed under the terms and conditions of the Creative Commons Attribution license (http://creativecommons.org/licenses/by/4.0/). 